\title{
Probiotic characterization of lactic acid bacteria isolated from swine intestine
}

\author{
K. Balasingham ${ }^{1}$, C. Valli ${ }^{2}$, L. Radhakrishnan ${ }^{3}$ and D. Balasuramanyam ${ }^{1}$
}

1. Postgraduate Research Institute of Animal Sciences, Tamil Nadu Veterinary and Animal Sciences University, Chennai, Tamil Nadu, India; 2. Institute of Animal Nutrition, Tamil Nadu Veterinary and Animal Sciences University, Chennai, Tamil Nadu, India; 3. Central Feed Technology Unit, Tamil Nadu Veterinary and Animal Sciences University, Chennai, Tamil Nadu, India.

Corresponding author: C. Valli, e-mail: valliviba@yahoo.co.in

Co-authors: KB: krish.balasingham@gmail.com, LR: radhakrish67@yahoo.com, DB: dbsagb@yahoo.com Received: 03-01-2017, Accepted: 29-05-2017, Published online: 28-07-2017

doi: 10.14202/vetworld.2017.825-829 How to cite this article: Balasingham K, Valli C, Radhakrishnan L, Balasuramanyam D (2017) Probiotic characterization of lactic acid bacteria isolated from swine intestine, Veterinary World, 10(7): 825-829.

\begin{abstract}
Aim: A study was conducted with the objective to isolate probiotic microorganisms from swine intestine.

Materials and Methods: In this study 63 isolates (24 caeca, 24 colon mucosal scrapings, and 15 rectal swab samples) were collected from Large White Yorkshire pigs. The isolates were inoculated and grown in de Man Rogosa Sharpe broth at $37^{\circ} \mathrm{C}$ with $5 \% \mathrm{CO}_{2}$ for $48 \mathrm{~h}$ and subjected to morphological identification. Colonies having Gram-positive rods were selected for further physiological and biochemical identification tests, which were conducted in triplicate in two runs for each of the selected isolates using a standard protocol. Probiotic properties among the identified species were determined through the implementation of several tests related with $\mathrm{pH}$ tolerance, bile tolerance, and antimicrobial activity.
\end{abstract}

Results: Morphological identification revealed that only 23 isolates were Gram-positive rods. Physiological tests performed on these 23 isolates further revealed that four of them did not exhibit any growth, at all conditions studied. The rest 19 isolates were, therefore, selected and subjected to biochemical tests. Six isolates were rejected because they were oxidase and nitrate reduction positive. From the 13 isolates subjected to sugar fermentation tests, speciation of only two isolates could be ascertained, one of the isolates showed characteristics for Lactobacillus acidophilus and the other for Lactobacillus plantarum. These two isolates were assessed for the strain possessing maximum probiotic property, and it was inferred that both - L. plantarum and $L$. acidophilus could tolerate a wide $\mathrm{pH}$ range $(2-9)$, a wide bile concentration $(0.05-0.3 \%)$ and revealed antimicrobial activity toward Escherichia coli, and Enterobacter spp.

Conclusion: L. plantarum and L. acidophilus were isolated from swine intestine and were found to have good probiotic properties.

Keywords: Lactobacillus acidophilus, Lactobacillus plantarum, probiotic, swine intestine.

\section{Introduction}

Antibiotics have been widely used for growth parameters in swine [1]. As a result, improved feed efficiency and increased economic returns in swine production were observed. However, pork consumers are increasingly concerned about antibiotic residues in pork [2] and the continuous use of antibiotics could lead to an increased bacterial resistance [3]. Moreover, European Union has banned the use of antibiotics as growth promoters since 2006. Due to these concerns probiotics could play an important role as alternatives to antibiotics in growth promotion.

The contemporary definition of a probiotic is "a microorganism which, when administered in adequate amounts, confers a health benefit on the host" and as living microorganisms, induces no drug resistance or

Copyright: Balasingham, et al. Open Access. This article is distributed under the terms of the Creative Commons Attribution 4.0 International License (http://creativecommons.org/licenses/ by/4.0/), which permits unrestricted use, distribution, and reproduction in any medium, provided you give appropriate credit to the original author(s) and the source, provide a link to the Creative Commons license, and indicate if changes were made. The Creative Commons Public Domain Dedication waiver (http:// creativecommons.org/publicdomain/zero/1.0/) applies to the data made available in this article, unless otherwise stated. drug residues [4]. Evidence has emerged that probiotics may promote growth, improve feed efficiency, prevent diarrhea and regulate the immune system in pigs. These positive effects are caused by a competitive exclusion of pathogenic bacteria through the colonization of beneficial bacteria in gastrointestinal tract [5]. The prerequisite for a probiotic to favor animals' performance is the colonization in the gut which is best attained if the organism being administered originates from the gut of same species.

In recent years, numerous probiotic strains have been used in pig production. The application of probiotics provides an alternative strategy to the use of antibiotics [6]. It is well known that not all probiotics are effective in pigs; therefore the selection of the right one is the most time-consuming part of developing a probiotic feed additive that is suitable for pigs [7]. There is, therefore, a need for a host target-specific probiotic strain, screened by appropriate in vitro methods that would potentially show enhanced in vivo efficacy when administered to livestock as a feed additive [8]. Recently, increased research into the development of probiotics for humans and animals has confirmed that probiotic action may be influenced by the host [9]. 
The genus Lactobacillus could play the role as a probiotic bacterium. This organism is a significant commensal of the normal gut microbiota of mammals and predominant at the early stage of pig gut microflora construction [8].

A study was therefore conducted, to prepare a probiotic preparation specific to swine, by isolating and characterizing the lactic acid bacteria from swine intestine.

\section{Materials and Methods \\ Ethical approval}

This study required no ethical approval as the collection of samples were from animals slaughtered for food purpose. All the other experiments were in vitro.

\section{Sample collection}

A total of 24 caeca and 24 colon mucosal scrapings were collected immediately after slaughter from 12 male Large White Yorkshire pigs (9-12 months of age) reared in Postgraduate Research Institute in Animal Sciences, Tamil Nadu Veterinary and Animal Sciences University, India. The animals before slaughter were fed swine finisher ration formulated to have $16 \%$ crude protein and $3170 \mathrm{Kcal} / \mathrm{kg}$ of metabolizable energy. 15 rectal swab samples were collected from 15 live Large White Yorkshire pigs maintained in the same institute. In total, 63 samples vis-a-vis isolates were collected.

\section{Morphological identification}

The isolates were inoculated and grown in de Man Rogosa Sharpe (MRS) broth at $37^{\circ} \mathrm{C}$ with $5 \%$ $\mathrm{CO}_{2}$ for $48 \mathrm{~h}$ and subjected to morphological identification [10].

\section{Physiological and biochemical tests}

Colonies having Gram-positive rods were selected for further physiological (growth at $\mathrm{pH} 4.5$ and $\mathrm{pH} 9.5$, and at $\mathrm{NaCl}$ concentration $2 \%$ and $6.5 \%$ ) and biochemical analyses (catalase, nitrate reduction, oxidase, Voges-Proskauer, and production of ammonia from arginine tests, which were carried out in triplicate in two runs for each of the selected isolate using standard protocol as mentioned in manual for the identification of medical bacteria by Cowan and Steel) [11].

\section{Sugar fermentation tests}

Sugar fermentation test [12] was carried out in triplicate in two runs for each of the selected isolates to identify the Lactobacillus species. The sugars used in the identification of Lactobacillus species were glucose, lactose, arabinose, fructose, esculin, galactose, maltose, mannitol, mannose, melibiose, raffinose, rhamnose, salicin, sorbitol, sucrose, trehalose, and xylose. Each bacterium has its own collection of enzyme that enables it to use diverse carbohydrate; this is often exploited in the identification of bacterial species. Thus, carbohydrate fermentation tests are essential for speciation of bacteria.
In vitro assays to select Lactobacillus possessing maximum probiotic properties

Probiotic properties among the identified species were determined through $\mathrm{pH}$ tolerance test $(\mathrm{pH} 2$, $2.5,3,4,5,8$, and 9$)$, bile tolerance test $(0.05 \%$, $0.1 \%, 0.15 \%, 0.2 \%$, and $0.3 \%)$ test [13], and the measurement of antimicrobial (Escherichia coli and Enterobacter spp.) activity [14]. The above tests were carried out in triplicate for each of the isolates.

\section{Statistical analysis}

The data collected on various parameters were grouped and subjected to statistical analysis by oneway ANOVA using SPSS, version 20.0 for Windows (2011) [15].

\section{Results}

Morphological identification of the isolates revealed that only 23 isolates were Gram-positive rods. Only these isolates were selected for physiological tests. Physiological tests performed on these 23 isolates revealed that four isolates exhibited no growth, irrespective of the examined conditions (pH: 4.5, 9.5; temperature; $15,45^{\circ} \mathrm{C}$; and $\mathrm{NaCl}: 2$, $6.5 \%$ ). Hence, only 19 isolates were selected and subjected to biochemical tests. During the implementation of the biochemical tests, six isolates were rejected on account that they were oxidase and nitrate reduction positive. From the remaining 13 isolates that were selected and subjected to sugar fermentation tests, speciation of only two isolates could be ascertained. One of the isolates showed characteristics for Lactobacillus acidophilus and the other for Lactobacillus plantarum.

These two isolates (L. acidophilus and L. plantarum) were assessed for the strain possessing maximum probiotic property, viz., $\mathrm{pH}$ tolerance, bile tolerance, and antimicrobial activity.

The optical density of MRS medium containing L. plantarum and L. acidophilus at various $\mathrm{pH}$ was measured at $2 \mathrm{~h}$ intervals at $650 \mathrm{~nm}$ (data are presented in Figures-1 and 2, respectively).

The optical density of MRS medium containing L. plantarum and Lactobacillus acidophilus at various bile concentration (\%) was also measured at $2 \mathrm{~h}$ intervals at $650 \mathrm{~nm}$ (data are shown in Figures-3 and 4, respectively).

It was, thus, concluded that both $L$. plantarum and $L$. acidophilus could tolerate a wide $\mathrm{pH}$ range (2-9), and a wide bile concentration (0.05-0.3\%). L. plantarum showed significantly $(\mathrm{p}<0.05)$ higher growth compared to L. acidophilus at all $\mathrm{pH}$ and all bile concentration tested.

The antimicrobial activity of Lactobacillus species as demonstrated by the inhibition zone produced $(\mathrm{mm})$ in the agar well diffusion assay is presented in Table-1.

Both L. plantarum and L. acidophilus revealed antimicrobial activity toward E. coli and Enterobacter spp. However, the antimicrobial activity of 


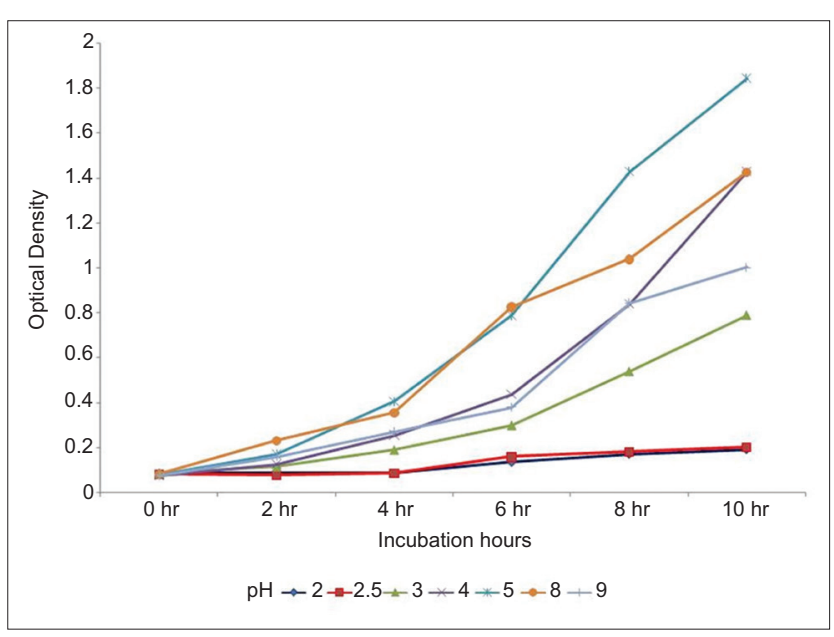

Figure-1: Optical density of de Man Rogosa Sharpe medium containing Lactobacillus plantarum at various $\mathrm{pH}$ measured at 2 hourly intervals at $650 \mathrm{~nm}$.

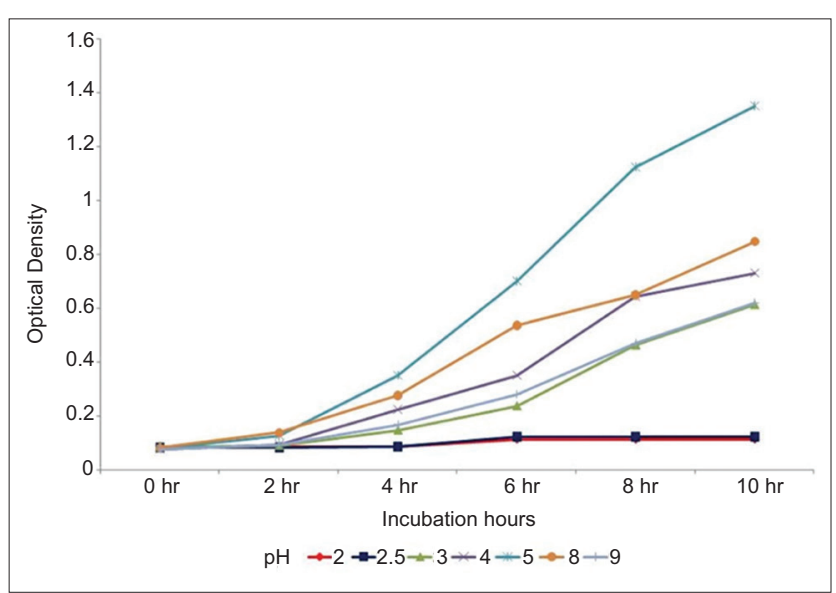

Figure-2: Optical density of de Man Rogosa Sharpe medium containing Lactobacillus acidophilus at various $\mathrm{pH}$ measured at 2 hourly intervals at $650 \mathrm{~nm}$.

Table-1: Antimicrobial activity of Lactobacillus spp. as demonstrated by the inhibition zone produced $(\mathrm{mm})$ in the agar well diffusion assay (mean* $\pm \mathrm{SE}$ ).

\begin{tabular}{lcc}
\hline Probiotic organisms & \multicolumn{2}{c}{ Pathogenic bacteria } \\
\cline { 2 - 3 } & Escherichia coli & Enterobacter \\
\hline Lactobacillus plantarum & $18.00^{\mathrm{a}} \pm 0.58$ & $18.33 \pm 0.33$ \\
Lactobacillus acidophilus & $20.00^{\mathrm{b}} \pm 0.59$ & $18.00 \pm 0.58$ \\
\hline
\end{tabular}

*Mean of six observations. Means bearing different superscripts within a column differ significantly $(p<0.05)$. SE: Standard error

L. acidophilus was significantly $(\mathrm{p}<0.05)$ higher compared to $L$. plantarum against $E$. coli.

\section{Discussion}

In this study, the probiotic properties of L. plantarum and L. acidophilus isolated from pig intestine were shown.

Multidimensional approaches that combine morphological and biochemical data are important for the accurate classification of lactic acid bacteria [16]. Hence, morphological, physiological, and

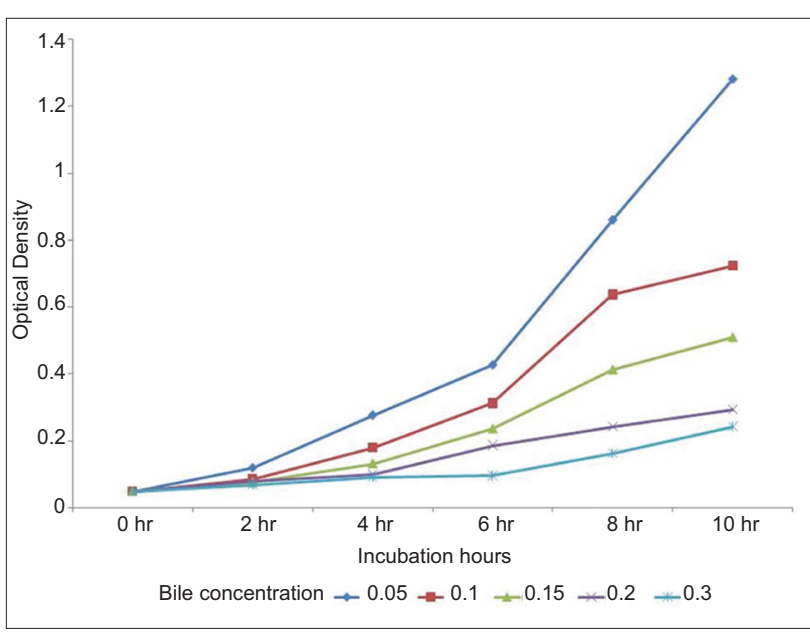

Figure-3: Optical density of de Man Rogosa Sharpe medium containing Lactobacillus plantarum at various bile concentrations measured at 2 hourly intervals at $650 \mathrm{~nm}$.

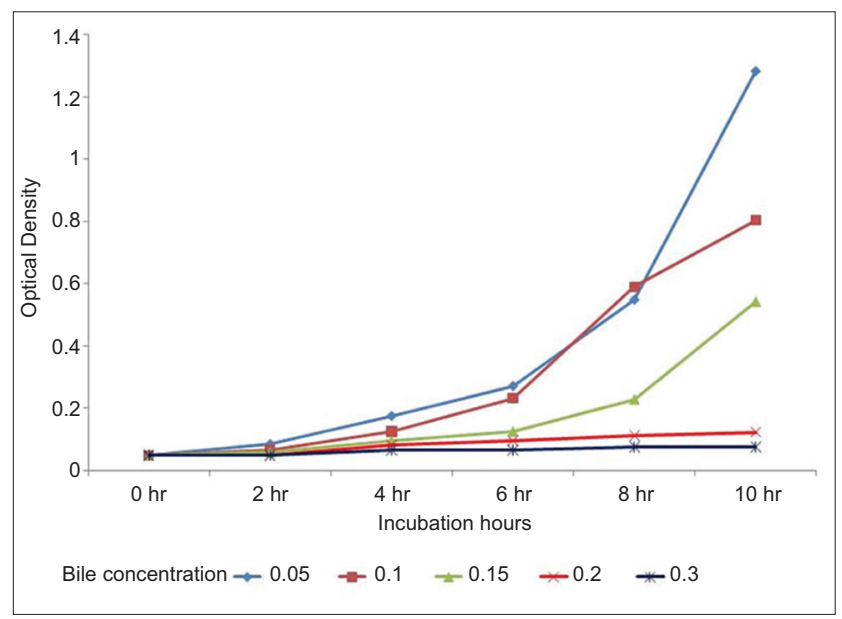

Figure-4: Optical density of de Man Rogosa Sharpe medium containing Lactobacillus acidophilus at various bile concentrations measured at 2 hourly intervals at $650 \mathrm{~nm}$.

biochemical tests were carried out in this study to isolate Lactobacilli from the multiple organisms present in pig intestine. Furthermore, carbohydrate fermentation tests were performed for speciation of isolated bacterial strains.

After the oral administration of probiotic organism, it is subjected to stressing conditions from the host which begins in the stomach with an acid $\mathrm{pH}$ between 1.5 and 3 and in the upper intestine and colon where high concentration of bile is encountered. It is, therefore, necessary that an efficient probiotic is capable of growing in an acidic environment and high concentration of bile [17]. As it was shown in this study.

Both L. plantarum and L. acidophilus could tolerate a wide $\mathrm{pH}$ range (3-9), thus fulfilling the criteria that probiotic organisms have to tolerate low $\mathrm{pH}$ and also should be capable of growing in a wide range of pH 1-9 [18]. Pyar and Peh [19] had, however, reported that Lactobacillus preferred to grow in acidic and neutral environment.

Bile tolerance is another crucial property for probiotic bacteria as it determines the ability of the 
organism to survive in the small intestine and consequently regulates the capacity of the probiotic to play a functional role [20]. Both L. plantarum and L. acidophilus could tolerate a wide bile concentration (0.05-0.15\%) indicating that both organisms have good probiotic properties. As in this study, it has been demonstrated [21] that when the concentration of bile salts increased there was a decrease in the viability of probiotic organisms. The reason for the reduced growth with increasing level of bile salts could be due to the binding of probiotic organism with bile salts [22].

In this study, both L. plantarum and L. acidophilus showed antimicrobial activity against E.coli and Enterobacter spp. The antimicrobial activity could have been due to the effect of organic acids [23] or the production of bacteriocins, which possesses high antimicrobial activity [24]. The production of organic acid and hydrogen peroxide by Lactobacilli was reported to inhibit growth of both Gram-positive and Gram-negative bacteria, whereas that of bacteriocin only the growth of Gram-positive bacteria [21].

\section{Conclusion}

L. plantarum and L. acidophilus were isolated from swine intestine, were found to have satisfactory probiotic properties and could be further exploited as host specific probiotics in swine.

\section{Authors' Contributions}

The work was carried out by $\mathrm{KB}$ as part of MVSc., Research Program, CV, was chairman and LR and DB were the members of advisory committee. All authors read and approved the final manuscript.

\section{Acknowledgments}

The authors wish to acknowledge Tamil Nadu Veterinary and Animal Sciences University, India, for financially supporting this study. The study is a part of MVSc., dissertation, submitted by first author to Tamil Nadu Veterinary and Animal Sciences University, India.

\section{Competing Interests}

The authors declare that they have no competing interests.

\section{References}

1. Thacker, P.A. (2013) Alternatives to antibiotics as growth promoters for use in swine production: A review. J. Anim. Sci. Biotechnol., 4: 35.

2. Vondruskova, H., Slamova, R., Trckova, M., Zraly, Z. and Pavli, I. (2010) Alternatives to antibiotic growth promotors in prevention of diarrhea in weaned piglets: A review. Vet. Med., 55: 199-224.

3. Van der Fels-Klerx, H.J., Puister-Jansen, L.F., van Asselt, E.D. and Burgers, S.L. (2011) Farm factors associated with the use of antibiotics in pig production. J. Anim. Sci., 89, 1922-1929.

4. Idoui, T. (2014) Probiotic properties of Lactobacillus strains isolated from gizzard of local poultry. Iran. J. Microbiol., 6(2): $120-126$
5. Wang, S.D., Yang, L., Tang, X.S., Cai, L.C., Liu, G., Kong, X.F., Blachier, F. and Yin, Y.L. (2011) Dietary supplementation with high dose Bacillus subtilis or Lactobacillus returi modulates cellular and humoral immunities and improve performance in weaned piglets. J. Food Agric. Environ., 9: 181-187.

6. Hou, C., Zeng, X., Yang, F., Liu, H. and Qiao, S. (2015) Study and use of the probiotic Lactobacillus reuteri in pigs: A review. J Anim. Sci. Biotechnol., 6(1): 14.

7. Jorgensen, J.N. and Hansen, C.H. (2006) Probiotics for pigs-reliable solutions. Int. Pig Top., 21(7): 7-9.

8. Yeo, S., Lee, S., Park, H., Shin, H., Holzapfel, W. and Huh, C.S. (2016) Development of putative probiotics as feed additives: Validation in a porcine-specific gastrointestinal tract model. Appl. Microbiol. Biotechnol., 100(23): 10043-10054.

9. Vlasova, A.N., Kandasamy, S., Chattha, K.S., Rajashekara, G. and Saif, L.J. (2016) Comparison of probiotic Lactobacilli and Bifidobacteria effects, immune responses and rotavirus vaccines and infection in different host species. Vet. Immunol. Immunopathol., 172: $72-84$.

10. Kandler, O. and Weiss, N. (1986) Regular, non sporing gram-positive rods. In: Sneath, P.H.A., Mair, N.S., Sharpe, M.E., Holt, J.G., editors. Bergey's Manual of Systematic Bacteriology. Williams, Wilkins, Baltimore. p1208-1260.

11. Cowan, M. and Steel, M. (2003) In: Barrow, G.I. and Feltham, R.K.A., editors. Manual for the Identification of Medical Bacteria. 3rd ed. Cambridge University Press, Cambridge, UK. p21-45 and 75-77.

12. Lan, Y., Verstegen, M.W.A., Tamminga, S. and Williams, B.A. (2005) The role of the commensal gut microbial community in broiler chickens. World Poult. Sci. J., 61: 95-104.

13. Todorov, S.D., Furtado, D.N., Saad, S.M.I., Gombossy, B.D. and Franco, M. (2011) Bacteriocin production and resistance to drugs are advantageous features for Lactobacillus acidophilus La-14, a potential probiotic strain. New Microbiol., 34(4): 357-370.

14. Sirilun, S., Chaiyasut, C., Kantachote, D. and Luxananil, P. (2010) Characterization of non-human origin probiotic Lactobacillus plantarum with cholesterol lowering property. Afr. J. Microbiol. Res., 4(10): 994-1000.

15. IBM Corp. (2011) SPSS Statistics for Windows, Version 20.0. IBM Corp, Armonk, NY.

16. Erdogrul, O. and Erbilr, F. (2006) Isolation and characterization of Lactobacillus bulgaricus and Lactobacillus casei from various foods. Turk. J. Biol., 30: 39-44.

17. Kali, A., Srirangaraj, S. and Charles, P.M. (2015) A cost effective carbohydrate fermentation test for yeast using micrititre plate. Indian J. Med. Microbiol., 33(2): 293-295.

18. Chowdhury, A., Hossain, N.M.D., Mostazir, J.N., Fakruddin, M.D. and Billah, M.M.D. (2012) Screening of Lactobacillus spp. from buffalo yoghurt for probiotic and antibacterial activity. J. Bacteriol. Parasitol., 3(8): 1-5.

19. Pyar, H. and Peh, K.K. (2014) Characterization and identification of Lactobacillus acidophilus using biolog rapid identification system. Int. J. Pharm. Pharm. Sci., 6(1): 975-1491.

20. Ruiz, L., Margolles, A. and Sánchez, B. (2013) Bile resistance mechanisms in Lactobacillus and Bifidobacterium. Front. Microbiol. Phys. Metabol., 4(1-8) 396-398.

21. Klayraung, S., Viernstein, H., Sirithunyalug, J. and Okonogi, S. (2008) Probiotic properties of Lactobacilli isolated from Dhai traditional food. Sci. Pharm., 76(3): 485-503.

22. Patel, H.M., Pandiella, S.S., Wang, R.H. and Webb, C. (2004) Influence of malt, wheat and barley extracts on the bile tolerance of selected strains of Lactobacilli. Food Microbiol., 21: 83-89.

23. Khunajakr, N., Wongwicharn, A., Moonmangmee, D. and 
Tantipaiboonvut, S. (2008) Screening and identification of lactic acid bacteria producing antimicrobial compounds from pig grastro intestinal tracts. KMITL Sci. Technol. J., 8(1): 8-17.
24. Aween, M.M., Hassan, Z., Muhialdin, B.J., Noor, H.M. and Eljamel, Y.A. (2012) Evaluation on antibacterial activity of Lactobacillus acidophilus strains isolated from honey. Am. J. Appl. Sci., 9: 807-817.

\section{$* * * * * * * *$}

